\title{
Factors Related to Thrombotic Microangiopathies in Pregnancy: an Integrative Review
}

Francisco Fábio Rodrigues Gomes ${ }^{1}$, Kelsen dos Santos Sales ${ }^{1}$, Antônio Fernandes Filho ${ }^{2}$ Maria do Carmo Andrade Duarte de Farias ${ }^{3}$, Anne Milane Formiga Bezerra ${ }^{4}$, Kévia Katiúcia Santos Bezerra ${ }^{3}$, Paula Christianne Gomes Gouveia Souto Maia ${ }^{3}$, Maria Soraya Pereira Franco Adriano ${ }^{5}$

\section{Abstract}

Introduction: Pregnancy is a state that can precipitate the occurrence of a thrombotic microangiopathy (TMA), characterized by the presence of microangiopathic hemolytic anemia and the existence of thrombi in the microcirculation. Conditions not very common, but that determine high maternal and fetal morbidity and mortality, as Hemolytic Uremic Syndrome (HUS), Thrombotic Thrombocytopenic Purpura (TTP) and Hemolysis Elevated Liver Enzymes, and Low Platelet Count (HELLP) syndrome.

Objective: Identifying factors related to the occurrence of thrombotic microangiopathy in pregnancy, based on the analysis of scientific production.

Method: An integrative review of literature, using the descriptors thrombotic microangiopathy, pregnancy, thrombotic microangiopathy, pregnancy; the consulted databases were PubMed, LILACS and SciELo with six articles published between 2003 and August 2014. The results were shown in summary frames.

Results: Evidence points to the failure in the cleavage of multimers of von Willebrand factor (FvW), due to deficiency of plasma metalloprotease ADAMTS13 in TTP; endothelial activation as responsible for hemolytic thrombotic state, which occurs in the diathesis gravidarum HELLP syndrome and the alternative pathway of complement dysregulation involved in atypical aspect of the HUS are the main
1 Bachelor's degree in Medicine from the Academic Unit of Life Sciences, Federal University of Campina Grande.

Cajazeiras, Paraíba, Brazil.

2 Academic Unit of Nursing, Teacher training center, Federal University of Campina Grande. Cajazeiras, Paraíba, Brazil.

3 Academic Unit of Life Sciences, Teacher training center, Federal University of Campina Grande. Cajazeiras, Paraíba, Brazil.

4 Nurse in the Mobile Emergency Service, MSU, Sousa, PB, Brazil.

5 Federal University of Paraíba. João Pessoa, Paraíba, Brazil.

\section{Contact information:}

Maria do Carmo Andrade Duarte de Farias.

Federal University of Campina Grande. Academic Unit of Life Sciences, Teacher training center. Cajazeiras, Paraíba, Brazil.

Address: Federal University of Campina Grande. Rua Sérgio Moreira de Figueiredo, sn Bairro Casas Populares, Cajazeiras, PB CEP 58900-000.

Đ carmo.andrade@ufcg.edu.br 
pathophysiological mechanisms involved in the TMA. But sometimes the differentiation between these three microangiopathic syndromes is difficult to perform, the remaining penumbra of intersectional or undifferentiated states; and often to supportive therapy more effective way of handling such disorders.

Conclusion: The spectrum of diseases that make up the thrombotic microangiopathy in pregnancy have multifactorial trait and much remains to be unveiled on its real pathophysiological mechanism, as well as the differentiating factors between the TMA in order to provide better clinical management in the future.

\author{
Keywords \\ Pregnancy; Hematological \\ Complications in Pregnancy; \\ High-Risk Pregnancy; \\ Risk Factors; Literature Review.
}

\section{Introduction}

Pregnancy is a period of the life cycle characterized by physiological changes of the maternal organism, ranging from structural and anatomical changes to functional changes in various organs and systems [1]. Nevertheless, many pathological conditions may be secondary or exacerbated by pregnancy, such as thrombotic microangiopathy (TMA) and Hemolysis Elevated Liver Enzymes, and Low Platelet Count (HELLP) syndrome, not very common conditions but which determine high maternal and fetal morbidity and mortality [2].

The TMA is characterized by the presence of microangiopathic hemolytic anemia and the existence of thrombi, compounds, mostly by fibrin and platelets in the microcirculation of various organs, especially the brain and kidney. There may be swelling of endothelial cells, with accumulation of cellular debris and proteins in subendothelial layer, causing a detachment of the cell basement membrane [3].

HELLP syndrome, characterized by microangiopathic hemolysis, thrombocytopenia and elevated liver enzymes, is a likely serious complication of pre-eclampsia, which determines kidney damage, brain, liver and placenta at different levels depending on the degree of microangiopathic lesions [2].
This syndrome is also considered an TMA in which fibrin thrombi are evident in liver biopsies, in affected patients [4].

The pathophysiology of HELLP syndrome is not yet fully elucidated. Disorders including this syndrome, thrombotic thrombocytopenic purpura (TTP), hemolytic uremic syndrome (HUS) and acute fatty liver of pregnancy (AFLP) have been proposed as spectrum of the same disease process. The common pathophysiologic link seems to injury/endothelial dysfunction with consequent vasospasm, activation-aggregation, platelet consumption and decrease the release of endothelium-derived relaxing factor, performing main pathophysiological role [5].

Non-specific thrombotic microangiopathy pregnancy represented mainly by thrombotic thrombocytopenic purpura (TTP) and hemolytic uremic syndrome (HUS) are rare disorders during pregnancy and postpartum [2].

Nonetheless, the pregnancy is a factor that can precipitate the occurrence of a thrombotic microangiopathy, accounting for $8 \%$ to $18 \%$ of all cases TMA [6], showing high morbidity and mortality up to $10 \%[7]$.

The TMA during pregnancy may be associated with deficiency of ADAMTS13, plasma metalloprotease cleavage of von Willebrand factor (VWF) in 
the case of TTP; deregulation of the complement system, in the case of atypical HUS (aHUS); to endothelial dysfunction with liver damage in the case of HELLP syndrome [8]. However, it is important to note that studies show that neither the deficiency of complement regulators or the deficiency of ADAMTS13 are sufficient in order to develop aHUS or TTP [9].

The TMA associated with ADAMTS13 deficiency occurs, in most cases, between the second and third trimester of pregnancy [10], and can be due to the progressive decrease of this metalloproteinase, and the concomitant increase antigen von Willebrand factor (vWF) which typically occurs during pregnancy [11]. It is precisely between the second and third trimester of pregnancy where it is observed lower activity of ADAMTS13 the proportion of Von Willebrand factor antigen, which probably enhances the inhibitory effect of anti-ADAMTS13 autoantibodies, leading to the TTP [10].

In women genetically predisposed, pregnancy can also be because of the deregulation of the alternative pathway C3 convert complement with hyperactivation, causing endothelial damage and promoting TMA. These events are seen mainly during the postpartum period, especially when complicated by infections or bleeding, featuring the aHUS. These patients are seen mutations in genes that produce the complement regulatory proteins, highlighting the factor $\mathrm{H}(\mathrm{CFH})$, factor I (CFI) [10].

The maternal morbidity is generally high in pregnancies complicated by TTP or HUS, mortality rate approaching $60 \%$ before the plasma infusion therapy, and plasmapheresis. However, recent series cases showed a mortality rate of $10 \%$. This significant reduction in mortality is attributable mainly to the early diagnosis, including mild forms of TTP, including women with probable eclampsia or HELLP syndrome, and improved therapeutic measures, such as plasma exchange and immunosuppression. In general, maternal survival is increased when there is a previous history of TTP/HUS before pregnancy, as these patients are followed closely with serial plasmapheresis and plasma exchange, if necessary. In contrast, maternal mortality is high in patients who develop complications for the first time during pregnancy and postpartum, occurring a delay in diagnosis because of the similarities with the HELLP syndrome, among other medical conditions, and the appropriate treatment instituted in stages most advanced disease [12].

The objective is to identify, from analysis of scientific production, factors related to TMA during pregnancy.

\section{Method}

It is an integrative literature review, because it allows the synthesis of several published studies, allowing the construction of new knowledge. It allows the inclusion of research adopting different methodologies, both experimental and non-experimental, featuring extensive analysis. It is performed in six stages [13]:

\section{Stage 1: Determination of the theme and selecting the search issue}

The preparation of the integrative review begins by defining a problem and formulating a research question that has relevance to health. HELLP syndrome is a topic often discussed in the literature, in addition to presenting important incidence in the population, especially in absolute terms. The differential diagnosis of thrombotic microangiopathy not specific to pregnancy (HUS/TTP) is difficult and often unattainable. But despite the rarity of these conditions, have high maternal and fetal morbidity and mortality. Thus, the central question of this study was: What factors related to thrombotic microangiopathy in pregnancy?

\section{Stage 2: Establishment criteria for sample selection} On August 11st, 2014, a survey was conducted by searching in the databases of the Virtual Health 
Library (VHL): LILACS (Latin American and Caribbean Health Sciences) and SciELO (Scientific Electronic Library Online) and base international data PUBMED (Medical Published - service of the US National Library of Medicine), using the following keywords: thrombotic microangiopathy, pregnancy, thrombotic microangiopathy, pregnancy.

The inclusion criteria of articles were published in Portuguese, English and Spanish, with abstracts and full text available on the selected databases in the period between 2003 and 2014. The search in PUBMED was done using the keywords mentioned in English, and they have been found 1426 articles. To refine your search, the filters were added: free full text, custom range (August 11, 2003 on August 11 2014), humans, languages (Portuguese, Spanish and English), Systematic Reviews, Clinical Trial Comparative Study a total of 86 items. In LILACS 6 articles were found using the descriptors thrombotic microangiopathy and pregnancy. In SciELO, the search using the thrombotic microangiopathy descriptors and pregnancy did not find any article. To improve access to articles there was used microangiopathy keyword thrombotic alone resulting in 13 articles.

\section{Stage 3: Identification of pre-selected and selected studies}

To carry out this stage was made initially reading the titles and abstracts, and 35 pre-selected articles in PubMed; later, it was carried out thorough reading of the pre-selected articles and verified their suitability for inclusion criteria of the study. Then, the closure of bibliographical material was obtained and the consolidation of findings to facilitate discussion and conclusion of the study. Articles from SciELO and LILACS were not pre-selected for addressing up to narrative reviews on the subject. After reading the pre-selected articles were selected only 6 PubMed articles.

\section{Stage 4: Categorization of selected studies}

This step is similar to data collection conducted in conventional surveys. For this, we used a previously validated instrument [14], containing the following items: identification of the original article, methodological characteristics of the study, assessment of the methodological rigor of measured interventions and findings. Thus, it was possible individualized analysis of each study, making it possible to sort them and synthesize them categorically.

\section{Stage 5: Analysis and interpretation of results}

It was carried out the interpretation and discussion of the evidence found in the selected texts, rising existing knowledge of inquiries and proposals for future research regarding the series.

\section{Stage 6: Presentation of knowledge synthesis}

The evidences were summarized and compared, and questioned the conclusions of the studies, according to its limitations.

\section{Results}

Frame 1 shows the relationship of the reviewed articles, with their titles, periodicals, and years of publication and level of evidence.

All articles were in English, five were published in the United States [10, 15-18] and only one [19] is a European publication, the oldest was the year 2003 [19] and the latest year 2012 [15].

Most of the articles addressed the pathophysiological factors related to thrombotic microangiopathy in pregnancy, and clinical and epidemiological characteristics. However, no study was conducted in Brazil, hampering the understanding of these diseases in our population, which has very heterogeneous and different sociodemographic population.

Newspapers that published the articles belonged to three areas of medicine. Three publications in 
Frame 1. Characterization of the publications reviewed.

\begin{tabular}{|r|l|c|}
\hline Article & \multicolumn{1}{|c}{ Title (Journal - Year) } & Evidence Level \\
\hline [10] & $\begin{array}{l}\text { Pregnancy-associated hemolytic uremic syndrome revisited in the era of complement gene } \\
\text { mutations. } \\
\text { (Journal of the American Society of Nephrology - 2010) }\end{array}$ & 3 \\
\hline [15] & $\begin{array}{l}\text { Unexpected frequency of Upshaw-Schulman syndrome in pregnancy-onset thrombotic } \\
\text { thrombocytopenic purpura. } \\
\text { (Blood - 2012) }\end{array}$ & 2 \\
\hline [16] & $\begin{array}{l}\text { The diagnostic dilemma of thrombotic thrombocytopenic purpura/hemolytic uremic syndrome } \\
\text { in the obstetric triage and emergency department: lessons from } 4 \text { tertiary hospitals. } \\
\text { (American journal of obstetrics and gynecology - 2009) }\end{array}$ & 4 \\
\hline [17] & $\begin{array}{l}\text { Factor H, membrane cofactor protein, and factor I mutations in patients with hemolysis, } \\
\text { elevated liver enzymes, and low platelet count syndrome. } \\
\text { (Blood - 2008) }\end{array}$ & 2 \\
\hline [18] & $\begin{array}{l}\text { Thrombotic thrombocytopenic purpura in 166 pregnancies: 1955-2006. } \\
\text { (American journal of obstetrics and gynecology - 2008) }\end{array}$ & 8 \\
\hline [19] & $\begin{array}{l}\text { Mild to moderate reduction of a von Willebrand factor cleaving protease (ADAMTS-13) in } \\
\text { pregnant women with HELLP microangiopathic syndrome. } \\
\text { (Haematologica - 2003) }\end{array}$ & 2 \\
\hline
\end{tabular}

Source: Made by the authors. PubMed, 2003-2014.

hematology newspapers (Blood) [15, 17]; one publication in Haematologica in [19]; two publications in obstetrics and gynecology journal (American journal of obstetrics and gynecology) [16, 18]; a publication in nephrology journal (Journal of the American Society of Nephrology) [10].

The method used in the articles was the cohort study [15, 17, 19], case-control [10], systematic review, with case series [18], clinical studies [16].

\section{Factors related to Thrombotic Microangiopathies in pregnancy}

Frame $\mathbf{2}$ expresses the synthesis of evidence referred to in the reviewed articles, listed according to the related TMA. Factors related to thrombotic microangiopathy, in obstetrics, referred to by the authors were: Change ADAMTS13 activity [15, 19], pregnancy $[10,15-16,18]$, maternal age $[10,15]$, parity $[10,15]$, laboratory abnormalities [15, 18], alternative pathway of the complement abnormalities [15, 17]. Importantly, due to the rarity of the diseases in question, not all evidence can be proven with statistical significance.
Frame 2. Characterization of publications as the factors related to thrombotic microangiopathies in pregnancy.

\begin{tabular}{|c|c|}
\hline Article & Factors related to the TMA in pregnancy \\
\hline \multirow[t]{5}{*}[10]{} & $\begin{array}{l}\text { - Mutation in genes involved in the control of the } \\
\text { alternative pathway of complement. }\end{array}$ \\
\hline & - Low levels of C3. \\
\hline & - Early adulthood. \\
\hline & - Gestational age. \\
\hline & - Parity. \\
\hline \multirow[t]{4}{*}{ [15] } & - Deficiency of ADAMTS13. \\
\hline & - Genetic mutation in the gene of ADAMTS13. \\
\hline & - Early adulthood. \\
\hline & - Parity. \\
\hline \multirow[t]{2}{*}[16]{} & - TTP in earlier pregnancies. \\
\hline & - Gestational age. \\
\hline$[17]$ & $\begin{array}{l}\text { - Mutation in one of } 3 \text { genes (CFH, CFI, MCP) } \\
\text { that codify regulating the alternative pathway } \\
\text { of complement. }\end{array}$ \\
\hline \multirow[t]{2}{*}[18]{} & - Pre-eclampsia. \\
\hline & - Pregnancy. \\
\hline$[19]$ & - Decreased activity of ADAMTS13. \\
\hline & ource: Made by the authors. PubMed, 2003-2014. \\
\hline
\end{tabular}


Frame 3. Factors that aid in the differential diagnosis of TMA.

\begin{tabular}{|c|c|c|c|}
\hline Article & HELLP syndrome & TTP & aHUS \\
\hline \multirow[t]{4}{*}{ [19] } & - Greater hepatic involvement & - Greater involvement of SNC & - \\
\hline & - Antithrombin and D-dimero abnormal & - Antithrombin and D-Dimer Normal & - \\
\hline & $\begin{array}{l}\text { - ADAMTS } 13 \text { activity decreased, but } \\
\text { more than } 10 \%\end{array}$ & $\begin{array}{l}\text { - ADAMTS13 decreased or less than } \\
10 \%\end{array}$ & - \\
\hline & - Absence of gmFvW in plasma & - Presence of gmFvW in the plasma & - \\
\hline [18] & - Late gestational age & - Early gestational age & - \\
\hline \multirow[t]{3}{*}{ [16] } & -Activity of ADAMTS13 greater than 10\% & - & - \\
\hline & - Significantly elevated liver transaminases & $\begin{array}{l}\text { - Normal or slightly elevated liver } \\
\text { transaminases }\end{array}$ & $\begin{array}{l}\text { - Normal or slightly elevated } \\
\text { liver transaminases }\end{array}$ \\
\hline & - & -Early gestational age & -Post-parturition \\
\hline
\end{tabular}

Source: Made by the authors. PubMed, 2003-2014.

For better understanding of the factors related to TMA during pregnancy, the evidence was also categorized regarding the differential diagnosis (Frame 3).

\section{Discussions}

Regarding the level of evidence, three papers [15, $17,19]$ used strong evidence considered methodology (level II), since, for addressing risk factors or related factor, the cohort study presents strong evidence, only succeeding systematic review of cohort studies (level I). Also an observational, case-control study (level III) [10], also retrospective, it presents good evidence on issues that address rare diseases or inquiries [20-21].

Exploring the evidence related to thrombotic microangiopathies during pregnancy, publications showed that the gestational period of occurrence for these gestational diseases presented different incidences between microangiopathy. An increased susceptibility to TTP was evidenced in the second half of pregnancy, especially the second trimester, corresponding to more than half of cases $[15,16$, 18]. In contrast, the occurrence of HUS was superior in the postpartum period [10].

The superimposed TTP to HELLP syndrome presented occurrence significantly later in pregnancy, compared to TTP, without evidence for HELLP
$(28.9 \pm 8$ weeks vs $23.6 \pm 9$ weeks, $p<0.05)$, by the second and third trimesters early [18]. In fact, the HELLP syndrome presents later occurrence during pregnancy, proven in a study of 442 pregnancies with HELLP, in which 89\% occurred from 27 weeks gestation [22]. Thus, the diagnosis of TTP should be raised if the thrombotic microangiopathy develop in the first half of pregnancy (mean gestational age of 23.5 weeks), since HELLP syndrome develop later and HUS typically develops in the post-partum [23].

The overlap between TTP and HELLP syndrome was also related to the significant increase of maternal mortality, compared to TTP no evidence for HELLP (44.4\% vs. $21.8 \%, p<0.02)$ [18]. Similarly, maternal mortality was significantly higher in patients who developed first TTP during pregnancy, compared with recurrent disease (26\% vs. $10.7 \%$ ). Probably, this increase in maternal mortality is related to the delay in initiation of appropriate treatment, due to the diagnostic confusion, in which $85.7 \%$ of cases TTP/HUS treated in the emergency services and obstetric screening were initially diagnosed as other clinical conditions and the HELLP syndrome main initial diagnosis. Furthermore, maternalfetal results were more favorable, the smaller the diagnostic latency period to the beginning of the plasmapheresis [16]. Despite the pregnancy present this clear differentiation between microangiopathy, becoming a helper factor in diagnostic suspicion, 
both TTP as HUS may develop at any time during pregnancy, as noted in the articles of this review.

Laboratory differentiation was also demonstrated for patients with TTP associated with HELLP syndrome, as less severe anemia, a lower ratio of lactate dehydrogenase (LDH) and aspartate aminotransferase (AST), and AST and its initial peak values 2 to 4 times higher compared to TTP patients without pre-eclampsia [18]. Proportional relationship between elevated liver enzymes and thrombocytopenia can also be a tool for the differential diagnosis in HELLP syndrome [16].

Also there was showed greater hepatic impairment in patients with HELLP, and greater neurological impairment in patients with TTP. They emphasized that in TTP, anemia and thrombocytopenia are more severe when compared in HELLP syndrome. Help, even in diagnosis, levels of antithrombin and D-dimer, which are changed in HELLP, intravascular coagulation compensated signals, and are in normal TTP intravascular coagulation uncompensated signals [19].

The TTP initiated during pregnancy also showed differentiation with respect to recurrent disease. The first had lower average values of hematocrit (19\% vs. 25\%) and hemoglobin (6.8 vs. $11.4 \mathrm{~g} / \mathrm{dL}$ ), compared to cases of recurrent disease $(p<0.02)$ [18]. Revealing that in addition to higher morbidity due to delayed diagnosis, there is also more severe hematological profile, sickness started during pregnancy.

The HUS during pregnancy was associated with severe renal impairment, requiring hemodialysis, in $81 \%$ of patients in the acute phase of the disease; besides evolution to terminal renal disease in more than half of cases. In contrast, no patient showed neurological symptoms and thrombocytopenia was moderate in $40 \%$ of cases. Furthermore, the serum C3 levels were low in the first assessment of complement in $57 \%$ of patients [10].

However, hepatic, neurological and renal manifestations are not unique to HELLP, TTP and HUS, respectively, because it may cause extra-renal manifestations associated. Although clinical evidence of thrombotic microangiopathy is limited to kidneys, neurological symptoms, e.g., may be present [24]. Guide the differential diagnosis based on the main clinical manifestation is one way.

The importance of alternative pathway activation in the genesis of P-aHUS, may explain the high incidence of mutations that occur in the regulation of the alternative pathway C3 converts in patients with aHUS in pregnancy. This complement dysregulation may have its greatest prominence in the postpartum period, when there was no more compensation for the fetal complement regulatory factors, inherited by his father, as well as inflammation, due to childbirth; Release in the maternal circulation of fetal cells, leading to infection and bleeding alternative pathway activation, which in the absence of effective regulatory mechanisms, ultimately, induce postpartum aHUS [16]. The different distribution of changes in factor $\mathrm{H}$ gene between cases of aHUS during pregnancy and not related to pregnancy, still needs clarification, but suggests there pathophysiological significance.

The activity of metalloprotease ADAMTS13 differ between women with TTP, compared to affected by HELLP syndrome. Pregnant women with HELLP syndrome had levels of ADAMTS-13 less than healthy pregnant women; but metalloproteinase activity was always greater than $10 \%$ different from that found in TTP, when activity levels are sometimes undetectable or less than 10\%. However, they emphasize that levels above $10 \%$ does not exclude the diagnosis of TTP. The study is the analysis of plasma levels of large multimers VonWillebrand factor (gmFvW); The results show that patients with HELLP syndrome do not have in their plasma gmFvW, unlike patients with TTP, in which the large multimers are found in plasma [19]. A possible explanation for this is that levels above $10 \%$ of ADAMTS13 activity in HELLP syndrome are sufficient to avoid the presence of gmFvW plasma. 
It was observed that the TTP in pregnancy was related, mostly, to young adults, with a mean age of 29 years; $75 \%$ of them belonged to the white ethnic group; and $76 \%$ were first pregnancy [15]. Proportionally, observed a greater relationship with white ethnic group in patients affected with HELLP syndrome, and mean age similar involvement of (24.4 \pm 5.6 years) [22]. Similarly, the average value for maternal age was similar in patients with aHUS during pregnancy. However, $38 \%$ of patients with only one child [10].

The results for the newborns were strongly related to gestational age, with the first and second quarters showing higher fetal morbidity and mortality. According to the authors [15], 76\% of pregnant women had acquired the form of TTP and were autoimmune; and 24\%, the inherited form, Upshaw-Schulman Syndrome (USS); patient with the USS had in common, mutations in ADAMTS13, affecting its synthesis

Among the articles that highlighted the deregulation of the supplement as a predisposing factor, a publication [10] showed mutations in complement regulatory genes in $86 \%$ of patients with aHUS in pregnancy, the most common mutation in the genes factor $\mathrm{H}$. The percentage of changes SCR19-20 segment located in factor $\mathrm{H}$ gene was significantly lower in patients with aHUS associated with pregnancy compared to those with aHUS unrelated to pregnancy.

Mutations in the regulatory genes SCR19-20 complement factor $\mathrm{H}$ and factor I genes were associated with a lower frequency of P- aHUS, compared with mutations in genes C3, MCP and segment SCR1-18 factor $\mathrm{H}$. Furthermore, the risk related to the development of aHUS during pregnancy in patients with these mutations regulators of complement genes was higher in the second pregnancy [17].

In 2008, patients were studied with HELLP syndrome and concluded that there was an abnormal control of the alternative complement pathway, identifying mutations in genes factor $\mathrm{H}$ and factor I. Draws attention, in this study, the mutation in the gene MCP A304V because this mutation has been reported in patients with atypical Hemolytic Uremic Syndrome. Thus, although aHUS and HELLP syndrome are two distinct TMA, the study indicated that the HELLP syndrome may be part of the expansion of disorders associated with dysregulation of the alternative complement pathway spectrum [17].

It was evident during the reading and review of selected studies, that there is duality in the polls. On the one hand the seeking approximate HELLP syndrome, TTP and aHUS within a single spectrum, categorizing the clinical similarities and particularly pathophysiological. This is the case of survey of patients who had diagnostic criteria for HELLP syndrome, but the authors looked for similarities that could approach the other microangiopathy [19]. Accordingly, they sought to show that the microvascular manifestations of patients could be associated with decreased ADAMTS13 activity (well established in patients with TTP).

In turn, researchers [17] showed that there is evidence of mutations in genes causing disruption in the alternative complement pathway (documented in the pathophysiology of aHUS). However, it highlighted the importance of establishing a definitive diagnosis, since treating this group of diseases within the same spectrum increases the morbidity and mortality of patients, especially due to the difference in treatment because the therapeutic approaches to TTP and aHUS are different [16]. But there is no disagreement among authors as to the resolution of pregnancy, as primordial conduct in the management of patients with HELLP syndrome.

Analysis of articles draws attention to that before a pregnant woman with microangiopathic hemolytic anemia and thrombocytopenia, should include it in thrombotic microangiopathy, as often before intersectional states and clinical dubiety, conduct based solely on epidemiological frequency, without the possibility of differential diagnosis among the full range of the group of TMA diseases, can frustrate the efforts and result in serious consequences for the mother-fetus. This doubt may occur, for exam- 
ple, in patients who are diagnosed to HELLP syndrome and then progress to worsening of neurological function. This patient would have HELLP syndrome and later evolved with TTP? Or is it possible that from the beginning of the clinical manifestations were already part of thrombotic thrombocytopenic purpura? In fact, there is still no answer to such questions.

\section{Synthesis of knowledge}

Pregnancy is one factor that may precipitate the occurrence of a thrombotic microangiopathy, which although not a common event, it is of high maternal and fetal morbidity and mortality, need to be guided quickly and accurately. The TMA can be grouped into major subtypes such as those related to deficiency of ADAMTS13, deregulation complement, or of unknown or undetermined mechanism.

It is vital to pay attention to the possibility of the occurrence of a TMA in a pregnant woman. Rapid laboratory tests, specific and sensitive for establishing the diagnosis are potentially useful for clinical management of patients. But sometimes the differentiation between the three great microangiopathic syndromes is difficult to perform, the remaining penumbra of intersectional or undifferentiated states, and often therapy to supportive the most effective way of handling such complaints.

During the study it was observed that the most prevalent microangiopathy in pregnancy is HELLP syndrome, followed by TTP and the aHUS; and that some factors are well related to the occurrence of the decrease of the activity of the metalloproteinase ADAMTS13 and genetic mutations that alter the regulatory proteins of the alternative complement pathway.

Although most articles have used strong methodological designs evident to carry out the research, due to the rarity of the diseases in question and much closer study of difficulty during pregnancy, a lot of evidence could not be proven with statistical significance. Moreover, no study analyzed in this review was conducted nationwide (Brazil). This de- monstrates the importance of conducting research for understanding these diseases in our population, which has distinct demographic characteristics used in those articles.

\section{Conclusion}

We consider relevant the proposal to seek evidence in the literature about the factors related to thrombotic microangiopathy, as it allows greater knowledge about the subject and will help to obstetric professionals in decision-making. We believe this theme, though little discussed in theory; it should be remembered during the clinical reasoning, to establish diagnosis with severe pre-eclampsia, a condition more common and can, in many situations, be complicated by thrombotic microangiopathy.

During our research, we found that the scientific production involving the theme thrombotic microangiopathy in obstetrics is deficient during the explored period. Still, most of the studies found were not enough evidence to solve the doubts and anxieties on the subject. We believe that prospective cohort studies are possible at the national level, with multicenter support.

\section{References}

1. Souza Al, Batista Filho M, Ferreira LOC. Alterações hematológicas e gravidez. Rev. Bras. Hematol. Hemoter. [Internet]. 2002 Mar; 24(1): 29-36. Available from: http://www.scielo.br/scielo. php?script=sci arttext\&pid=S1516-84842002000100006\&lng=en. http://dx.doi.org/10.1590/S1516-84842002000100006

2. Hussein W, Lafayette RA. Renal function in normal and disordered pregnancy. Curr Opin Nephrol Hypertens. 2014 Jan; 23(1): 46-53. doi: 10.1097/01.mnh.0000436545.94132.52

3. Noris M, Remuzzi G. Thrombotic microangiopathy after kidney transplantation. Am J Transplant. 2010 Jul; 10(7): 1517-23. doi: 10.1111/j.1600-6143.2010.03156.x

4. Barton JR, Riely CA, Adamec TA, Shanklin DR, Khoury $A D$, Sibai BM. Hepatic histopathologic condition does not correlate with laboratory abnormalities in HELLP syndrome (hemolysis, elevated liver enzymes, and low platelet count). Am J Obstet Gynecol [Internet], 1992 Dec; 167(6): 1538-43. doi: http://dx.doi.org/10.1016/0002-9378(92)91735-S

5. Kirkpatrick CA. The HELLP syndrome. Acta clin Belg, 2010 MarApr; 65(2): 91-7. PMID: 20491358 
6. Fakhouri F, Vercel C, Frémeaux-Bacchi V. Obstetric nephrology: $A K I$ and thrombotic microangiopathies in pregnancy. Clin J Am Soc Nephrol, 2012 Dec; 7(12): 2100-6. doi: 10.2215/ CJN.13121211.

7. Vesely SK, George JN, Lämmle B, Studt JD, Alberio L, ElHarake MA, Raskob GE. ADAMTS13 activity in thrombotic thrombocytopenic purpura-hemolytic uremic syndrome: relation to presenting features and clinical outcomes in a prospective cohort of 142 patients. Blood, 2003 Jul 1; 102(1): 60-8. PMID: 12637323

8. Tsai HM. The molecular biology of thrombotic microangiopathy. Kidney int., 2006 Jul; 70(1): 16-23. PMID: 16760911

9. Kavanagh D, Goodship THJ, Richards A. Atypical haemolytic uraemic syndrome. British medical bulletin, 2006 Oct; 77(1): 5-22. doi: 10.1093/bmb/ldl004

10. Fakhouri F, Roumenina L, Provot F, Sallée M, Caillard S, Couzi L et al. Pregnancy-associated hemolytic uremic syndrome revisited in the era of complement gene mutations. J Am Soc Nephrol., 2010 May; 21(5): 859-67. doi: 10.1681/ASN.2009070706

11. Mannucci PM, Canciani MT, Forza I, Lussana F, Lattuada A, Rossi E. Changes in health and disease of the metalloprotease that cleaves von Willebrand factor. Blood, Nov 1; 98(9): 2730-5. PMID: 11675345

12. Sibai BM. Imitators of severe pre-eclampsia. Semin perinatol., 2009 Jun; 33(3): 196-205. doi: 10.1053/j.semperi.2009.02.004.

13. Botelho LLR, Cunha CCA, Macedo M. O método da revisão integrativa nos estudos organizacionais. Gestão e Soc, 2011 May-Aug; 5(11): 121-36. Available from: http://www. gestaoesociedade.org/gestaoesociedade/article/view/1220/906

14. Ursi SE, Galvão, CM. Perioperative prevention of skin injury: an integrative literature review. Rev. Latino-Am. Enfermagem, Ribeirão Preto Jan-Feb 2006; 14(10): 124-31. doi: http://dx.doi. org/10.1590/S0104-11692006000100017

15. Moatti-Cohen, M. et al. Unexpected frequency of UpshawSchulman syndrome in pregnancy-onset thrombotic thrombocytopenic purpura. Blood, v. 119, n. 24, p. 5888-5897, 2012.

16. 16 Stella, C. L. et al. The diagnostic dilemma of thrombotic thrombocytopenic purpura/hemolytic uremic syndrome in the obstetric triage and emergency department: lessons from 4 tertiary hospitals. Am J Obstet Gynecol [Internet], v. 200, n. 4, p. 381. e1-381. e6, 2009.

17. 17 Fakhouri, F. et al. Factor $\mathrm{H}$, membrane cofactor protein, and factor I mutations in patients with hemolysis, elevated liver enzymes, and low platelet count syndrome. Blood, v. 112, n. 12, p. $4542-4545,2008$

18. Martin JR, J. N. et al. Thrombotic thrombocytopenic purpura in 166 pregnancies: 1955-2006. Am J Obstet Gynecol [Internet], v. 199, n. 2, p. 98-104, 2008.

19. Lattuada, A. et al. Mild to moderate reduction of a von Willebrand factor cleaving protease (ADAMTS-13) in pregnant women with HELLP microangiopathic syndrome. Haematologica, v. 88, n. 9, p. 1029-1034, 2003.
20. EL DIB, R. P. Como praticar a medicina baseada em evidências. Jornal Vascular Brasileiro, Porto Alegre, v. 6, n. 1, p. 1-4, 2007. Disponível em: <http://www.scielo.br/pdf/jvb/v6n1/v6n1a01. pdf>. Acesso em 15 out. 2014.

21. Galvao, C. M.; Sawada, N. O.; Mendes, I. A. C. A busca das melhores evidências. Rev Esc Enferm USP, v. 37, n. 4, p. 43-50, 2003.

22. Sibai, B. M. et al. Maternal morbidity and mortality in 442 pregnancies with hemolysis, elevated liver enzymes, and low platelets (HELLP syndrome). Am J Obstet Gynecol [Internet], v. 169, n. 4, p. 1000-1006, 1993.

23. Shamseddine, A. et al. Thrombotic thrombocytopenic purpura and pregnancy: report of four cases and literature review. Journal of clinical apheresis, v. 19, n. 1, p. 5-10, 2004.

24. Siegler, R.; Oakes, R. Hemolytic uremic syndrome; pathogenesis, treatment, and outcome. Current opinion in pediatrics, v. 17, n. 2, p. 200-204, 2005.

\section{Comment on this article:}

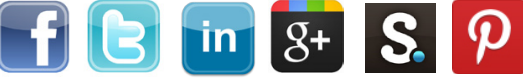

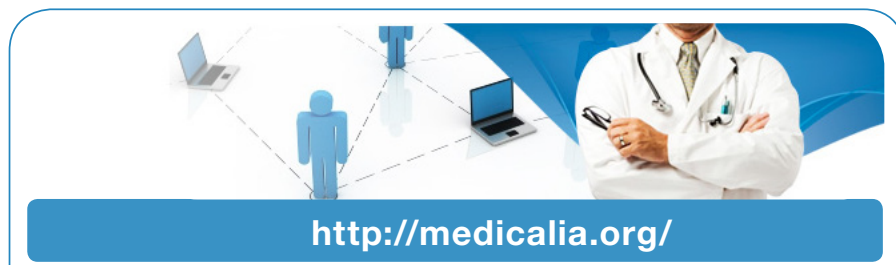

Where Doctors exchange clinical experiences, review their cases and share clinical knowledge. You can also access lots of medical publications for free. Join Now!

\section{Publish with iMedPub}

\section{http://www.imed.pub}

International Archives of Medicine is an open access journal publishing articles encompassing all aspects of medical science and clinical practice. IAM is considered a megajournal with independent sections on all areas of medicine. IAM is a really international journal with authors and board members from all around the world. The journal is widely indexed and classified Q1 in category Medicine. 